Objectives: Our aim was to analyze the association of HLA class II with HS in a Caucasian population from Cantabria (northern Spain).

Methods: In this study we analyzed the $H L A-A,-B,-C, D R B 1,-D Q A 1$ and $-D Q B 1$ allele distribution in $106 \mathrm{HS}$ patients and 262 age- and sex-matched controls from a Caucasian population of Cantabria (northern Spain).

Results: $H L A-A^{\star} 29$ and $B^{\star} 50$ were significantly more frequent in HS patients and $A^{\star} 30$ and $B^{\star} 37$ in controls, but these associations disappeared after correction. On the other hand, $D R B 1^{\star} 07, D Q A 1^{*} 02$ and $D Q B 1^{*} 02$ were significantly more frequent in controls ( $p$ 0.026, $p 0.0012$ and $p 0.0005$ respectively), and the $H L A$ allele $D Q B 1^{*} 03: 01$ was significantly more frequent in HS patients ( $p$ 0.00007) all of them after Bonferroni correction. Furthermore, the $D R B 1^{*} 07$; $D Q A 1^{\star} 02 ; D Q B 1^{\star} 02$ haplotype was significantly more frequent in controls (p 0.0005)

Conclusion: This is the first study showing an association of HLA-class II with $\mathrm{HS}$. Our results suggest that $\mathrm{HLA}$-II alleles $\left(D R B 1^{\star} 07, D Q A 1^{*} 02, D Q B 1^{*} 02\right.$ and $\left.D Q B 1^{\star} 03: 01\right)$ and the $D R B 1^{\star} 07 \sim D Q A 1^{*} 02 \sim D Q B 1^{\star} 02$ haplotype could influence on resistance or susceptibility to HS.

References:

[1] González-López MA. J Am Acad Dermatol. 2016; Aug;75(2):329-35

[2] González-López MA. PLoS One. 2018 Jan 4;13(1).

[3] Vilanova I. J Eur Acad Dermatol Venereol. 2018 May;32(5):820-824

[4] Durán-Vian C, et al. J Eur Acad Dermatol Venereol. 2019 Nov;33(11):2131-2136.

Disclosure of Interests: Monica Calderón-Goercke: None declared, J. Gonzalo Ocejo-Vinyals: None declared, Miguel A González-Gay Grant/research support from: Pfizer, Abbvie, MSD, Speakers bureau: Pfizer, Abbvie, MSD, Marcelo A. Fernández-Viña: None declared, Juan Cantos-Mansilla: None declared, losune Vilanova: None declared, Ricardo Blanco Grant/research support from: AbbVie, MSD, and Roche, Speakers bureau: AbbVie, Pfizer, Roche, Bristol-Myers, Janssen, and MSD, Marcos González-López: None declared

DOI: 10.1136/annrheumdis-2020-eular.4483

\section{AB0006 1 HYPOMETHYLATION OF THE PROMOTER REGION OF TLR4 GENE AT A SYSTEMIC LEVEL IN PATIENTS WITH RHEUMATOID ARTHRITIS AND PERIODONTITIS}

S. Chatterjee $^{1}$, D. Bhattacharjee ${ }^{1}$, S. Misra ${ }^{1}$, A. Rao ${ }^{1}$, A. Chattopadhyay ${ }^{2}$, A. Ghosh ${ }^{1} .{ }^{1}$ Institute of Post Graduate Medical Education and Research, Department of Rheumatology, Kolkata, India; ${ }^{2}$ Post Graduate Institute of Medical Education \& Research, Department of Rheumatology, Chandigarh, India

Background: Periodontitis (PD) has long been linked with Rheumatoid arthritis (RA) [1]. Epigenetic modifications are being recently explored to explain such associations, DNA methylation being one such important mechanism.

Objectives: To study the effect chronic generalized periodontitis on systemic methylation of TLR4 genes in comparison to only RA and RA with PD patients.

Methods: Twenty-three RA patients, among which 11 patients had chronic generalized $P D, 20$ patients with only $P D$ and 15 healthy individuals recruited. DNA was isolated from PBMCs of the participants blood, then were first bisulphite converted and then methylation specific PCR were performed using primers for methylated and um-methylated promoters of TLR4. The DNA amplifications were checked in horizontal gel electrophoresis. The methylation signatures were verified by DNA sequencing (Sanger) of the amplified products

Results: The anti-CCP, DAS-CRP and HAQ DI were higher in patients with both RA and PD $(220 \pm 40,5.7 \pm 0.2,1.5 \pm 0.1$ respectively, $\mathrm{p}<0.05)$. Control samples had shown amplification bands for methylated primers of TLR4 but not for un-methylated primers of TLR4. However, only RA, only PD and RA with PD samples, had shown amplification for un-methylated primers and not for methylated primers. These results together with DNA sequencing indicated that $4 \mathrm{CpG}$ sites in the promoter ofTLR4 genes were hypo-methylated in the PBMCs of patients whereas those remain methylated in healthy individuals.

Conclusion: The observations indicated that though PD is a localised disease of the gingiva there is a systemic involvement of TLR mediated pathways in them which is similar to those in RA. However, further validation in larger cohort and down-stream signalling molecules needs to be studied.

References:

[1] Ceccarelli F, Saccucci M, Di Carlo G, Lucchetti R, Pilloni A, Pranno N, Luzzi V, Valesini G, Polimeni A. Periodontitis and rheumatoid arthritis: the same inflammatory mediators?. Mediators of inflammation. 2019;2019.

Disclosure of Interests: None declared

DOI: 10.1136/annrheumdis-2020-eular.3455

\section{AB0007 VALUE OF ULTRASOUND IN ASSESSMENT OF ACTIVE SACROILIITIS IN PATIENTS WITH AXIAL SPONDYLOARTHRITIS}

M. Chen ${ }^{1}$, S. M. Dai ${ }^{1} .{ }^{1}$ Shanghai Jiao Tong University Affiliated Sixth People's Hospital, Department of Rheumatology and Immunology, Shanghai, China

Background: The inflammatory of the sacroiliac joints (SIJs) called sacroiliitis is a characteristic of axial Spondyloarthritis (axSpA). The detection of sacroiliitis is meaningful to prevent irreversible changes. The tool of assessment of sacroiliitis including radiographs, computed tomography (CT) and magnetic resonance imaging (MRI). Ultrasound (US) has also been used in the evaluation of sacroiliitis in recent years.

Objectives: We aimed to evaluate the value of US in the assessment of active sacroiliitis in axSpA patients.

Methods: Fifty-one patients fulfilling Assessment of SpondyloArthritis International Society (ASAS) 2009 criteria for the classification of axSpA were recruited ${ }^{1}$. All the patients underwent MRI and US evaluation of bilateral SIJs. MRI was performed using the sequences of T1WI, T2WI and fat suppression T2WI (FS-T2WI). MRI sacroiliitis was defined according to ASAS criteria of active sacroiliitis $^{2}$. The Spondyloarthritis research Consortium of Canada (SPARCC) scoring was used to evaluate the inflammatory lesions in $\mathrm{SIJs}^{3}$. US were performed by an ultrasonographer with 10 years of experience in musculoskeletal ultrasound, and resistive index (RI) value was recorded. The US sacroiliitis was defined as the presence of more flow signals at SIJ with an $\mathrm{RI} \leq 0.75$. The HLA$\mathrm{B} 27$, erythrocyte sedimentation rate (ESR) and hypersensitive C-reactive protein (hsCRP) were also evaluated. Consistency rate, sensitivity, specificity, positive predictive values (PPV) and negative predictive values (NPV)for the diagnosis of sacroiliitis by US were calculated, using MRI as the gold standard

Results: Of the 51 patients, 24 were female and 27 were male. The HLA-B27 positive rate was $90.2 \%$ (46/51). The consistency rate of US and MRI sacroiliitis was 55.88 (57/102). The sensitivity and specificity of US for the diagnosis of sacroiliitis were 55.93 (33/59) and 55.81 (24/43) respectively. The PPV and NPV were $63.46(33 / 52)$ and $48(24 / 50)$ respectively. There was no significant difference in ESR and hsCRP between the US positive sacroiliitis and the others $(P=0.7477$ and 0.2268 , respectively). The SPARCC scores have no significant difference between the US positive sacroiliitis and the others ( $P=$ $0.2206)$. The RI was not significantly associated with the MRI SPARCC score $(\mathrm{P}=0.4236)$.

Conclusion: US may be an optional method for preliminary screening sacroiliitis. But its reliability as a diagnostic method needs further verification.

References:

[1] Rudwaleit M, et al. The development of Assessment of SpondyloArthritis international Society classification criteria for axial spondyloarthritis (part II): validation and final selection. Ann Rheum Dis. 2009; 68(6):777-83

[2] Rudwaleit $M$, et al. Defining active sacroiliitis on magnetic resonance imaging (MRI) for classification of axial spondyloarthritis: a consensual approach by the ASAS/OMERACT MRI group. Ann Rheum Dis 2009;68(10):1520-7

[3] Maksymowych WP, et al. Spondyloarthritis research Consortium of Canada magnetic resonance imaging index for assessment of sacroiliac joint inflammation in ankylosing spondylitis. Arthritis Rheum.2005;53(5):703-9.

Acknowledgments: This project was supported by grants from National Natural Science Foundation of China (81900795)

Disclosure of Interests: None declared

DOI: 10.1136/annrheumdis-2020-eular.3990

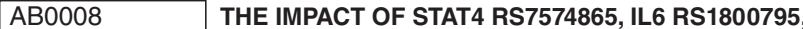 IL6R RS2228145 AND RS4845618 ON RHEUMATOID ARTHRITIS SUSCEPTIBILITY IN BELARUSIAN POPULATION}

E. Siniauskaya ${ }^{1}$, T. Kuzhir ${ }^{1}$, V. Yagur ${ }^{2}$, R. Goncharova ${ }^{1} .{ }^{1}$ Institute of Genetics and Cytology of NAS of Belarus, Minsk, Belarus; ${ }^{2}$ Belarusian State Medical University, Minsk, Belarus

Background: Rheumatoid arthritis (RA) is a chronic systemic disorder of the connective tissue of still unknown aetiology and complex autoimmune pathogenesis that primarily affects small joints. HLA alleles provide for $11-37 \%$ of the RA heritability, suggesting the substantial role of the non-HLA loci in genetic predisposition to RA. Among non-HLA loci, IL6, IL6R and STAT4 genes attract attention, however, the data concerning their influence on RA risk are somewhat contradictory.

Objectives: The aim of the study was to analyze the involvement of four SNPs (STAT4 rs7574865, IL6 rs1800795, IL6R rs2228145 and rs4845618) in RA susceptibility.

Methods: 187 patients diagnosed with RA (mean age $58.2 \pm 11.9$ ), and 380 healthy blood donors (mean age $37.18 \pm 10.69$ years) were included into the 
study. DNA extraction from peripheral blood samples was performed using the phenol-chloroform method. SNPs were genotyped using the real-time PCR with fluorescent probes. The allele and genotype frequencies were compared using the $x 2$ test. Odds ratios (ORs) and 95\% confidence intervals (95\% Cls) were calculated using the VassarStats online tool.

Results: Utilizing recessive genetic model we found an association between TT genotype of STAT4 rs7574865 (OR = 2.362; 95\%Cl [1.0378 - 5.376], $\mathrm{p}=0.038$ ) and RA. For IL6 rs1800795, it was found that CC genotype had significantly higher frequency among patients with rheumatoid arthritis as compared to that in controls $(\mathrm{OR}=1.52 ; 95 \% \mathrm{Cl}[1.02-2.27], \mathrm{p}=0.0456)$. No associations of IL6R rs2228145 and rs4845618 SNPs with risk of RA were found in the total group of patients vs. controls. It was also shown that IL6 rs 1800795 CC genotype frequency was significantly higher among the patients with RF-negative status ( $p=0.0019)$

Conclusion: Thus, we provide evidence for association of the STAT4 rs7574865 and IL6 rs 1800795 variants with risk of RA in the Belarusian population, some features of interplay being revealed between gene polymorphisms analyzed and RA antibody status. Abovementioned SNPs may contribute to RA genetic susceptibility in the Belarusian population.

Disclosure of Interests: None declared

DOI: 10.1136/annrheumdis-2020-eular.1990

\section{AB0009 ASSOCIATION BETWEEN POLYMORPHISMS OF BANK1 AND MANIFESTATIONS OF SLE}

D. D. González-Castillo ${ }^{1,2}$, R. E. Barbosa-Cobos ${ }^{1}$, G. E. Lugo Zamudio ${ }^{1}$, M. A. Saavedra ${ }^{3}$, R. E. Sánchez-Briones ${ }^{3}$, I. Alemán-Ávila ${ }^{4}$, J. Ramírez Bello ${ }^{4}$. ${ }^{1}$ Hospital Juárez de México, Rheumatology, Ciudad de México, Mexico; ${ }^{2}$ SENESCYT, Guayaquil, Ecuador; ${ }^{3}$ Centro Medico Nacional La Raza, Rheumatology, Ciudad de México, Mexico; ${ }^{4}$ Hospital Juárez de México, Unit of Research, Ciudad de México, Mexico

Background: BANK1 encodes an adapter/scaffold protein primarily expressed in $B$ cells, which is involved in cell signaling and activation. Genome-wide association studies (GWAS) have identified different BANK1 single nucleotide variants (SNVs) associated with SLE primarily in European or Asian-derived populations. Interestingly, we recently have documented an association between this gene and susceptibility to systemic lupus erythematosus (SLE) in Mexican population.

Objectives: To determine whether the BANK1 R61H (rs10516487G/A) and A383T (rs3733197G/A) SNVs are associated with clinical and immunological manifestations in SLE.

Methods: Our study included 123 Mexican women with SLE (SLICC 2012 criteria). Genotyping of the two BANK1 SNVs were obtained by TaqMan probes and real-time PCR. An association study was performed between the alleles and genotypes of BANK1 R61H and A383T with the clinical and immunological manifestations included in the SLE SLICC classification criteria. Hardy-Weinberg equilibrium and an association study was performed using Finetti, a $p$ value $\leq$ 0.05 indicated association.

Results: We identify an average age of $38.5 \pm 12$. Cases and controls remained in Hardy-Weinberg equilibrium. An association with susceptibility to SLE was found between genotypes of the two BANK1 SNVs and joint manifestations (rs1051487G/A; AA + GA vs GG, OR 4.45, $p=0.004$, rs3733197G/A; AA + GA vs GG, OR 2.66, $p=0.032$, respectively), as well as with protection for neurological and renal involvement (rs1051487G/A, OR 0.16, $p=0.02$, rs3733197G/A; OR $0.40, p=0.02$, respectively) (Table $1 \mathrm{a}$ and $b$ ). No association was found with other clinical manifestations.

Conclusion: Our data in the Mexican population show that both BANK1 R61H and A383T SNVs are risk factors for synovitis. On the other hand, these BANK1 $\mathrm{R} 61 \mathrm{H}$ and $\mathrm{A} 383 \mathrm{~T}$ variants are protective factors for neurological and renal damage, respectively.

References:

[1] Ramírez-Bello J, Jiménez-Morales S, Montufar-Robles I, et al. BLK and BANK1 polymorphisms and interactions are associated in Mexican patients with systemic lupus erythematosus. Inflamm Res. 2019;68:705-13

[2] J. De Azevêdo Silva, C. Addobbati, P. Sandrin-Garcia and S. Crovella. Systemic Lupus Erythematosus: Old and New Susceptibility Genes versus Clinical Manifestations. Current Genomics. 2014;15:52-65

[3] Sánchez E, Rasmussen A, Riba L, Acevedo E, Kelly J, Langefeld CD, et al. Impact of Genetic Ancestry and Socio-Demographic Status on the Clinical Expression of Systemic Lupus Erythematosus in Amerindian-European Populations. Arthritis Rheum. 2012; 64(11):3687-3694

[4] Castillejo-López C, Delgado-Vega AM, Wojcik J, et al. Genetic and physical interaction of the B-cell systemic lupus erythematosus-associated genes BANK1 and BLK. Ann Rheum Dis. 2012;71:136-42
[5] Kozyrev SV, Abelson AK, Wojcik J, et al. Functional variants in the B-cell gene BANK1 are associated with systemic lupus erythematosus. Nat Genet. 2008;40:211-6

Disclosure of Interests: None declared

DOI: 10.1136/annrheumdis-2020-eular.5141

\begin{tabular}{|l|l}
\hline AB0010 & TRIPLE DMARD TREATMENT IN EARLY RHEUMATOID \\
ARTHRITIS INCREASE SYNOVIAL ACTIVATED \\
NATURAL KILLERS AND RESTING MAST CELLS BUT \\
DECREASE PLASMA CELLS AND M1 MACROPHAGES
\end{tabular}

M. Y. Hachim ${ }^{1}$, N. M. Elemam ${ }^{1}$, I. Hachim ${ }^{1}$, S. Hannawi ${ }^{2}$, R. Hamoudi ${ }^{1}$, A. A. Maghazachi'. 'Sharjah Institute for Medical Research, College of Medicine, University of Sharjah, Sharjah, United Arab Emirates; ${ }^{2}$ Ministry of Health and Prevention, Department of Rheumatology, Dubai, United Arab Emirates

Background: Rheumatoid arthritis (RA) is a chronic inflammatory joint disease with cartilage and bone damage as well as disability and its optimal therapeutic success depends on understanding the underlying pathophysiology[1]. Since RA is a heterogenous disease, there is an urge to characterize new molecular mechanisms to aid the development of more effective and personalized therapy [2]. Genome-wide transcriptional effects of tDMARD in early RA synovial tissues showed alterations in gene expression of $\mathrm{T}$ cell activation and plasmablast/plasma cell differentiation[3]

Objectives: Using publicly available synovial tissue transcriptomic data to compare the immune cells infiltration at baseline and after 6 months of tDMARD to identify subgroups that might not respond well to tDMARD.

Methods: RNAseq dataset (GSE97165) of synovial biopsies taken from 19 early RA patients at baseline and after 6 months of tDMARD treatment were retrieved and reanalyzed. The raw RNAseq data were used for in silico prediction of the immune cells' infiltration the synovial tissue using CIBERSORT analytical tool to evaluate the pre versus post tDMARD changes in immune population and/or activation status. Then, patients were divided according to the level of alteration in immune cells percentage after the treatment. Differentially expressed genes between the subgroups were defined and gene set enrichment analysis was performed to identify the underlying pathways in each group using BioJupies tools.

Results: 4 immune cells populations showed significant changes after 6 months of tDMARD indicating their role in disease pathophysiology or in response to the therapy. Resting mast cells and activated natural killer (NK) cells were increased in $84 \%$ and $74 \%$ of patients, respectively. On the other hand, M1 macrophages and plasma cells were decreased after treatment in $68 \%$ and $58 \%$ of patients, respectively. GSEA of differentially expressed genes between patients who showed increased activated NK cells in comparison to those who showed decreased or no change in NK cells after treatment identify novel pathways that can explain the heterogeneity in response to treatment specifically genes related to WNT signaling, estrogen metabolism and IL17 signaling.
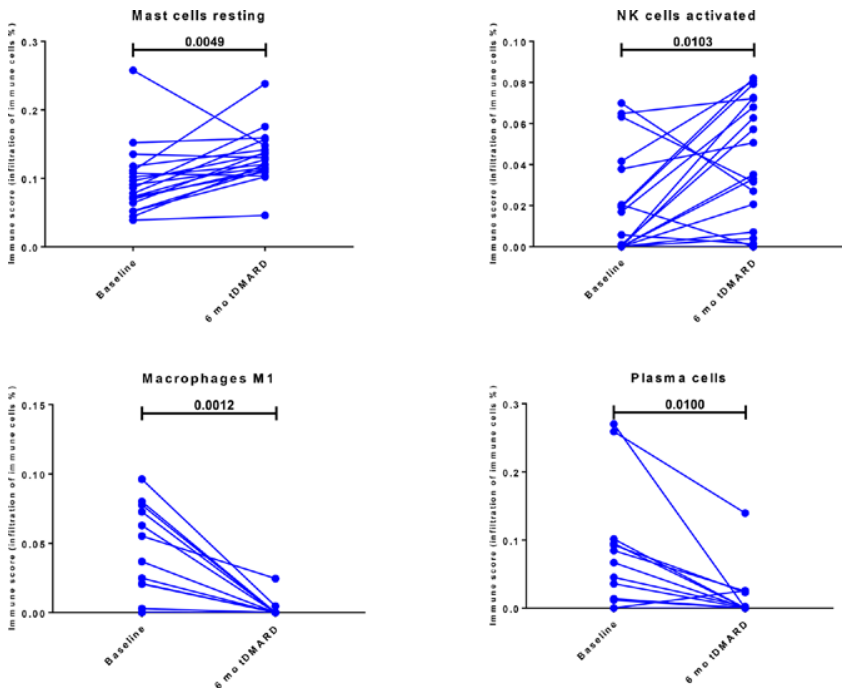

Figure 1. Percentage of infiltrating immune cells in the synovial tissue at baseline and after 6 months of tDMARD therapy in 19 early RA patients using CIBERSORT tool. 